\title{
Impact of completeness of revascularization by coronary intervention on exercise capacity early after acute ST-elevation myocardial infarction
}

Wei Zhao, Jin Bai, Fuchun Zhang, Lijun Guo and Wei Gao*

\begin{abstract}
Background: The importance of achieving complete revascularization by percutaneous coronary intervention (PCI) in patients with acute myocardial infarction (MI) on exercise capacity remains unclear.

Objective: To compare exercise capacity early after acute ST-elevation myocardial infarction (STEMI), in patients receiving $\mathrm{PCl}$ with stenting, between those completely revascularized (CR) and those incompletely revascularized (IR).

Methods: We retrospectively reviewed 326 patients [single-vessel disease (SVD) group, 118 patients; multivessel disease (MVD) with CR group, 112 patients; MVD with IR group, 96 patients] who underwent cardiopulmonary exercise testing 7-30 days after STEMI to measure peak oxygen uptake $\left(\mathrm{VO}_{2 \text { peak }}\right)$, oxygen uptake at anaerobic threshold $\left(\mathrm{VO}_{2 \mathrm{AT}}\right)$, and peak oxygen pulse. Demographic data, presence of concomitant diseases, STEMI characteristics, and echocardiography and angiography findings were evaluated.
\end{abstract}

Results: Most patients were male (89.0\%) and mean age was $55.6 \pm 11.2$ years. Ischemic ST deviation occurred in $7.1 \%$, with no significant difference between groups. $\mathrm{VO}_{2 \text { peak }}$ and $\mathrm{VO}_{2 \mathrm{AT}}$ did not differ significantly between groups, despite a trend to be lower in the CR and IR groups compared with the SVD group. Peak oxygen pulse was significantly higher in the SVD group than in the IR group $(p=0.005)$. After adjustment for age, gender, body mass index, cardiovascular risk factors, Ml characteristics and echocardiography parameters, CR was not an independent predictor of $\mathrm{VO}_{2 \text { peak }}(\mathrm{OR}=-0.123,95 \%$ confidence interval $[\mathrm{Cl}]-2.986$ to $0.232, \mathrm{p}=0.093), \mathrm{VO}_{2 \mathrm{AT}}(\mathrm{OR}=0.002,95 \% \mathrm{Cl}$ 1.735 to $1.773, p=0.983)$, or peak oxygen pulse $(\mathrm{OR}=-0.102,95 \% \mathrm{Cl}-1.435$ to $0.105, \mathrm{p}=0.090)$.

Conclusion: CR in patients with STEMI treated with PCl for multivessel disease might show no benefit on short-term exercise tolerance over IR.

Keywords: Myocardial infarction, Percutaneous coronary intervention, Angioplasty, Revascularization, Multivessel disease, Exercise capacity

\section{Background}

Primary percutaneous coronary intervention $(\mathrm{PCI})$ in the infarct-related artery (IRA) is now considered the gold standard for patients with acute ST-elevation myocardial infarction (STEMI) [1,2]. Multivessel disease (MVD) is relatively common in patients with STEMI, with a reported prevalence ranging from $50 \%$ in highly selected

\footnotetext{
* Correspondence: weigao@bjmu.edu.cn

Department of Cardiology, Peking University Third Hospital; Key Laboratory of Cardiovascular Molecular Biology and Regulatory peptides, Ministry of Health; Key Laboratory of Molecular Cardiovascular Sciences, Ministry of
Education, Beijing 100191, China Health; Key Laboratory of Molecular
Education, Beijing 100191, China
}

\section{Biomed Central}

subjects enrolled in randomized clinical trials, such as the CADILLAC study [3], to $80 \%$ in those included in more comprehensive registries or those with cardiogenic shock, such as in the SHOCK trial $[4,5]$. This high frequency raises important therapeutic and prognostic issues concerning whether to target revascularization therapy to the IRA only, or whether to include other vessels affected by stenosis. There are evidences that limiting PCI to the IRA has the advantages of a shorter procedure duration, decreased use of dye, and reduced incidence of peri-procedural myocardial infarction (MI), whereas targeting additional diseased arteries shows the 
advantages of decreased rate of recurrent angina, and a superior left ventricular ejection fraction (LVEF) [6]. Nonetheless, it is still unclear whether complete revascularization (CR) is superior, equivalent, or inferior to incomplete revascularization (IR), in terms of the riskbenefit balance.

Exercise capacity is a powerful predictor of all-cause mortality [7]. This premise appears to hold true in asymptomatic healthy individuals, as well as in populations of patients with a chronic disease [8]. Recently, several studies demonstrated that cardiopulmonary exercise testing (CPET) is a useful technique for the assessment of myocardial ischemia [9-11], and may be used as a method for measuring the effects of therapy $[12,13]$. Studies also showed that CPET has a prognosis value in MI patients [7-13].

Available data about the relative advantages and disadvantages of $C R$ and IR in patients with acute STEMI undergoing PCI with stenting is limited. The aim of this study was to use CPET within 30 days of STEMI to assess parameters reflecting exercise capacity (including peak oxygen uptake, $\left.\mathrm{VO}_{2 \text { peak }}\right)$, and to use these as outcome measures to compare the benefits of CR and IR in this cohort of patients. It was predicted that the results of our study would provide additional, useful information that would help guide clinicians making management decisions for patients with MVD requiring revascularization after STEMI.

\section{Methods}

\section{Study population}

The study protocol was conform to the ethical guidelines of the 1975 Declaration of Helsinki, and was approved by the Human Research Committee of the Peking University Third Hospital (Beijing, China), which waived the requirement for informed consent.

We selected our study population from a database, which contained 1600 patients admitted to the Peking University Third Hospital, China, between September 2007 and December 2011 for an acute STEMI. Inclusion criteria were: 1) acute STEMI; 2) successful primary PCI using drug-eluting stents; and 3) CPET performed within 7-30 days of STEMI onset. The clinical criteria used for STEMI diagnosis at the time of admission were: 1) chest pain persisting $\geq 30$ minutes; 2) ST-segment elevation of at least $0.1 \mathrm{mV}$ in $\geq 2$ contiguous electrocardiographic leads; and/or 3) increased levels of cardiac biomarkers (creatine kinase-MB, troponin-I, or troponinT). Exclusion criteria were: 1) cardiogenic shock at presentation (systolic blood pressure $\leq 90 \mathrm{mmHg}$ ); 2) pulmonary edema on admission; 3) previous MI; 4) pulmonary disease comorbidity (such as chronic obstructive pulmonary disease); or 5) previous revascularization procedure (PCI or coronary artery bypass grafting, CABG). After application of these criteria, 326 patients were available for analysis. Patients were included if their whole dataset was available.

Included patients were classified into 3 groups: a singlevessel disease (SVD) group $(n=118)$, a MVD with $C R$ group $(n=112)$, and a MVD with IR group $(n=96)$. Demographic data, comorbidities, STEMI characteristics, angiography findings, revascularization procedure, echocardiography data, and CPET results were evaluated.

\section{Catheterization protocol}

In all patients, diagnostic coronary angiography followed by PCI of the IRA was performed immediately after admission, using standard techniques. PCI of the IRA was based on angiography-guided decisions. The goal of PCI was to restore thrombolysis in myocardial infarction (TIMI) grade 3 flow with residual stenosis $<30 \%$. Achievement of this goal was defined as a successful procedure. Delayed PCI of the non-IRA was performed during the subsequent days of the index hospitalization. After primary PCI, all patients received $100 \mathrm{mg}$ of aspirin daily (indefinitely) and $75 \mathrm{mg}$ of clopidogrel daily (for one year), as well as $\beta$-blockers (BB), angiotensin-converting enzyme inhibitors (ACEI) or angiotensin receptor blockers (ARB), and statins, if these agents were not contraindicated.

The coronary arteries were classified based on anatomical criteria. The following vessels were considered as major coronary arteries: left main, left anterior descending, circumflex, and right coronary arteries. Diagonal, obtuse marginal, and intermediate branches were considered to be major branches. Lesions at a bifurcation were analyzed as if they were two diseased arteries. MVD was defined as the presence of $\geq 50 \%$ stenosis of $\geq 2$ major epicardial coronary arteries or their major branches, as assessed during initial coronary angiography. The coronary artery disease (CAD) severity in MVD patients was assessed according to a modified Gensini's stenosis scoring system [14]. This score is computed by assigning a severity score to each coronary stenosis based on the degree of luminal narrowing and its topographic importance. Reduction in lumen diameter was evaluated and assigned a score of 1 , $2,4,8,16$ and 32 for $25 \%, 50 \%, 75 \%, 90 \%, 99 \%$ and complete occlusion, respectively. A multiplier was also assigned to the value of each affected segment based on the functional significance of the myocardial area supplied by that segment: 5 for the left main coronary artery; 2.5 for the proximal segment of the left anterior descending artery; 2.5 for the proximal segment of the circumflex artery; 1.0 for the right coronary artery, the distal segment of the left anterior descending artery, the posterolateral artery and the obtuse marginal artery; and 0.5 for all other segments. 
CR was defined as the absence of total occlusion, with no residual stenosis of $>70 \%$ found in any major coronary artery or major branch, at discharge, based on visual assessment $[15,16]$. To validate the visual assessment, quantitative coronary angiography (QCA) was performed in 254 lesions and compared with visual assessment; there was no significant difference between the two methods $(\mathrm{P}=0.41$, data not shown $)$.

\section{Cardiopulmonary exercise testing}

Current guidelines recommend CPET during hospitalization or early after discharge [17-19]. CPET was performed in our patients with the primary aim of prognosis assessment, and to determine exercise intensity based on $\mathrm{VO}_{2 \max }$ and oxygen uptake at anaerobic threshold $\left(\mathrm{VO}_{2 \mathrm{AT}}\right)$. After a familiarization test, a symptom-limited CPET was performed within 7-30 days of STEMI, in a single-exercise laboratory. We used a modified Bruce treadmill protocol with continuous monitoring of 12 standard echocardiographic leads. Analysis of ventilatory expired gas was performed using a metabolic system (MAX-II, Physio-Dyne Instrument Corp., USA). The following endpoints were used for termination of the test: 1) achieving $85 \%$ of the predicted maximum heart rate for age; 2 ) respiratory exchange ratio $(\mathrm{RER}) \geq 1.1 ; 3$ ) presence of chest pain, dyspnea, dizziness, palpitations, leg pain or fatigue; 4) fall in systolic blood pressure of $10 \mathrm{mmHg}$ accompanied by symptoms of lightheadedness; 5) excessive systemic blood pressure increase to $\geq 230 / 130 \mathrm{mmHg}$; 6) sustained ventricular tachycardia or frequent runs of non-sustained ventricular tachycardia; or 7) horizontal or downsloping ST depression $\geq 0.2 \mathrm{mV}$. Test results were interpreted by two experienced evaluators who were blinded to: 1) patients' names; 2) other studies results; 3) patients' clinical history; and 4) physical findings.

An ischemic ST deviation was defined as ST depression, measured $0.08 \mathrm{~s}$ from the J point, of $0.1 \mathrm{mV}$ or more, and followed by more significant ischemia until the end of the test. The definition of $\mathrm{VO}_{2 \text { peak }}$ was the highest $\mathrm{O}_{2}$ consumption during any stage of maximal exercise that could be sustained for $30 \mathrm{~s}$. The $\mathrm{VO}_{2 \mathrm{AT}}$ was measured by the V-slope method [20]. The oxygen pulse was defined as the oxygen consumption per heart beat, and is related directly to the stroke volume according to the Fick formula: oxygen pulse $=$ stroke volume $\mathrm{x}$ (arterial - venous) oxygen.

\section{Statistical analysis}

Statistical analysis was performed using SPSS 20.0 for Mac (SPSS Inc., USA). Continuous parameters are expressed as mean \pm standard deviation (SD) unless otherwise specified; categorical variables are presented as numbers and proportions. For continuous variables, comparisons between groups were made using one-way analysis of variance (ANOVA), with a Fisher's LSD post-hoc test.
Categorical variables were compared using the Chi-square test. Relationships between CPET parameters, angiography findings, subject demographic features, STEMI characteristics, and cardiovascular risk factors were assessed using regression analyses. A p-value $<0.05$ was indicative of statistical significance.

\section{Results}

Participants' characteristics

Clinical characteristics of the participants are summarized in Table 1 . The majority of patients were male (89.0\%), mean age was $55.6 \pm 11.2$ years, $48.8 \%$ of patients had anterior wall MI, and the proportion of Killip Class I on admission was $97.2 \%$. There were no significant differences between the three groups in any characteristic, with the exception of hypertension: hypertension was more common in both the CR and IR groups than in the SVD group $(\mathrm{p}<0.05)$, but did not differ between the $C R$ and IR groups.

\section{Angiography and intervention}

Comparison of these data between the IR and CR groups revealed that patients with IR had a higher prevalence of three-vessel disease ( 57.3 vs. $31.3 \%, \mathrm{p}<0.001)$, and were managed using fewer stents $(1.6 \pm 0.7$ vs. $2.1 \pm 0.8$, $\mathrm{p}<0.001)$ than patients with $\mathrm{CR}$, including the stents from an eventual second PCI in the CR group (Table 1). Extent of baseline stenosis of the non-infarct-related lesions was similar between the CR and IR groups (CR: $83.3 \% \pm 11.7 \%$ vs. IR: $81.0 \% \pm 10.8 \%, \mathrm{p}=0.12$ ). There was no difference in Gensini's score between the two groups $(\mathrm{CR}=63.2 \pm 37.0$ vs. $\mathrm{IR}=65.2 \pm 36.5, \mathrm{P}=0.814)$.

\section{Stress electrocardiography and cardiopulmonary exercise testing}

Results of stress electrocardiography and CPET are shown in Table 2. Ischemic ST deviation occurred in $7.1 \%$ of patients, with a peak heart rate of $129.6 \pm 18.0 \mathrm{bpm}$. No significant differences were observed between the CR and IR groups with respect to any of the variables assessed (proportion of patients with ischemic ST deviation, peak heart rate, $\mathrm{VO}_{2 \text { peak }}, \mathrm{VO}_{2 \mathrm{AT}}$ and peak oxygen pulse). There were also no significant differences between the MVD groups (IR or CR) and the SVD group with regard to the proportion of patients with ischemic ST deviation, peak heart rate, $\mathrm{VO}_{2 \text { peak }}$ and $\mathrm{VO}_{2 \mathrm{AT}}$. However, there was a trend for $\mathrm{VO}_{2 \text { peak }}$ and $\mathrm{VO}_{2 \mathrm{AT}}$ to be lower in patients with MVD than in those with SVD (Table 2). The peak oxygen pulse was significantly different between the SVD and IR groups $(p=0.005)$, although no significant differences were observed between the CR group and either the SVD or IR groups. 
Table 1 Participants' characteristics

\begin{tabular}{|c|c|c|c|c|}
\hline & SVD $(n=118)$ & $C R(n=112)$ & IR $(n=96)$ & $p$-value \\
\hline Age, years & $52.7 \pm 11.1$ & $57.1 \pm 10.9$ & $57.3 \pm 11.0$ & 0.912 \\
\hline Male, n (\%) & $106(89.8)$ & $102(91.1)$ & $82(85.4)$ & 0.401 \\
\hline Hypertension, n (\%) & $42(35.6)$ & $54(48.2)^{*}$ & $57(59.4)^{*}$ & 0.002 \\
\hline Hyperlipidemia, n (\%) & $54(45.8)$ & $59(56.2)$ & $52(54.2)$ & 0.334 \\
\hline Diabetes mellitus, n (\%) & $17(14.4)$ & $18(16.1)$ & $23(24.0)$ & 0.175 \\
\hline Smoking, n (\%) & $85(72.0)$ & $80(71.4)$ & $62(64.6)$ & 0.052 \\
\hline $\mathrm{BMI}, \mathrm{kg} / \mathrm{m}^{2}$ & $25.9 \pm 3.2$ & $25.4 \pm 2.9$ & $26.3 \pm 3.0$ & 0.106 \\
\hline Anterior infarction, n (\%) & $67(56.8)$ & $53(47.3)$ & $39(40.6)$ & 0.059 \\
\hline Killip Class I on admission, n (\%) & $116(98.3)$ & $110(98.2)$ & $91(94.8)$ & 0.219 \\
\hline Maximum value of $\mathrm{CK}$, IU/L & $1421 \pm 801$ & $1370 \pm 770$ & $1460 \pm 879$ & 0.730 \\
\hline LVEDD, mm & $49.6 \pm 4.5$ & $49.3 \pm 6.8$ & $50.3 \pm 5.7$ & 0.401 \\
\hline LVEF,\% & $57.1 \pm 8.9$ & $57.3 \pm 10.1$ & $55.9 \pm 9.0$ & 0.592 \\
\hline Gensini's score & - & $63.2 \pm 37.0$ & $65.2 \pm 36.5$ & 0.814 \\
\hline IRA & & & & 0.080 \\
\hline LM, n (\%) & $0(0)$ & $0(0)$ & $0(0)$ & \\
\hline LAD, n (\%) & $70(59.3)$ & $57(50.9)$ & 38 (39.6) & \\
\hline LCX, n (\%) & $16(13.6)$ & $18(16.1)$ & $18(18.6)$ & \\
\hline RCA, n (\%) & $32(27.1)$ & $37(33.0)$ & $40(41.7)$ & \\
\hline \multicolumn{5}{|c|}{ Medication usage at the time of CPET, n (\%) } \\
\hline RAAS blockers & $102(86.4)$ & $98(87.5)$ & $88(91.7)$ & 0.467 \\
\hline B-blockers & $95(80.5)$ & $80(71.4)$ & $69(71.9)$ & 0.207 \\
\hline Statins & $101(85.6)$ & $95(84.8)$ & $80(83.3)$ & 0.900 \\
\hline
\end{tabular}

Values are presented as mean \pm SD. SVD, single-vessel disease; CR, complete revascularization; IR, incomplete revascularization; $B M I$, body mass index; CK, creatinine kinase; LVEDD, left ventricular end-diastolic diameter; LVEF, left ventricular ejection fraction; IRA, infarct-related artery; LM, left main coronary artery; LAD, left anterior descending coronary artery; LCX, left circumflex artery; RCA, right coronary artery; CPET, cardiopulmonary exercise testing; RAAS, renin-angiotensin-aldosterone system. ${ }^{*} \mathrm{p}<0.05$ compared with SVD group.

\section{Factors involved in exercise capacity}

Stepwise multiple regression analysis was performed to further evaluate the relationship between exercise capacity and the revascularization status of patients with MVD (i.e., those with either CR or IR). In particular, we were interested in determining whether $\mathrm{CR}$, as compared with IR, was a predictor of exercise capacity. The variables selected for the multivariate analysis included age, gender, BMI, hypertension, hyperlipidemia, diabetes mellitus, smoking, anterior wall MI, Killip class I, peak CK value, LVEDD, LVEF, and SVD, CR and IR. After adjustment for age, gender, body mass index (BMI), cardiovascular risk factors, MI characteristics and echocardiography parameters, CR was not found to be an independent predictor of $\mathrm{VO}_{2 \text { peak }}(\mathrm{OR}=-0.123,95 \%$ confidence interval [CI] -2.986 to $0.232, \mathrm{p}=0.093), \mathrm{VO}_{2 \mathrm{AT}}(\mathrm{OR}=0.002$, $95 \% \mathrm{CI}-1.735$ to $1.773, \mathrm{p}=0.983$ ), or peak oxygen pulse $(\mathrm{OR}=-0.102,95 \% \mathrm{CI}-1.435$ to $0.105, \mathrm{p}=0.090)$. However, as detailed in Table 3, gender, age and LVEF were predictors of $\mathrm{VO}_{2 \text { peak }}$, gender and anterior infarction were negatively correlated with $\mathrm{VO}_{2 \mathrm{AT}}$, and gender, age, BMI and LVEF were associated with peak oxygen pulse.

Table 2 Results of the ECG stress test and CPET

\begin{tabular}{lllll}
\hline & SVD $(\mathbf{n}=\mathbf{1 1 8})$ & CR $(\mathbf{n}=\mathbf{1 1 2})$ & IR $(\mathbf{n}=\mathbf{9 6})$ & p-value \\
\hline Ischemic ST deviation, $\mathrm{n}(\%)$ & $6(5.1)$ & $9(8.0)$ & $8(8.3)$ & 0.576 \\
Peak heart rate, bpm & $133.6 \pm 17.0$ & $128.6 \pm 18.2$ & $126.0 \pm 18.2$ & $20.1 \pm 5.4$ \\
$\mathrm{VO}_{2 \text { peak, }} \mathrm{ml} \cdot \mathrm{kg}^{-1} \cdot \mathrm{min}^{-1}$ & $23.4 \pm 5.5$ & $21.5 \pm 5.4$ & $19.0 \pm 4.8$ & 0.283 \\
$\mathrm{VO}_{2 \mathrm{AT}}, \mathrm{ml} \cdot \mathrm{kg}^{-1} \cdot \mathrm{min}^{-1}$ & $20.4 \pm 4.7$ & $19.0 \pm 4.5$ & $11.9 \pm 3.1^{*}$ & 0.089 \\
Peak oxygen pulse, $\mathrm{ml}^{*} \cdot \mathrm{beat}^{-1}$ & $13.2 \pm 3.3$ & $12.4 \pm 3.4$ & 0.016 \\
\hline
\end{tabular}

Values are presented as the mean \pm SD. SVD, single-vessel disease; $C R$, complete revascularization; IR, incomplete revascularization; $\mathrm{Vo}_{2 \text { peak, }}$ peak oxygen uptake; $\mathrm{Vo}_{2 \mathrm{AT}}$, oxygen uptake at anaerobic threshold. ${ }^{*} \mathrm{p}<0.05$ compared with SVD group. 
Table 3 Independent predictors of short-term exercise capacity after STEMI

\begin{tabular}{lll}
\hline & OR $(\mathbf{9 5} \% \mathrm{Cl})$ & p-value \\
\hline $\mathrm{VO}_{\text {2peak }}$ & & \\
Gender & $-3.932(-6.511$ to -1.353$)$ & 0.003 \\
Age & $-0.092(-0.167$ to -0.017$)$ & 0.016 \\
LVEF & $0.114(0.030$ to 0.199$)$ & 0.008 \\
$\mathrm{VO}_{2 \mathrm{AT}}$ & & \\
Gender & $-3.428(-6.755$ to -0.102$)$ & 0.044 \\
Anterior infarction & $-2.155(-3.874$ to -0.436$)$ & 0.014 \\
Peak oxygen pulse & & \\
Gender & $-3.386(-4.690$ to -2.107$)$ & $<0.001$ \\
Age & $-0.043(-0.079$ to -0.006$)$ & 0.022 \\
BMl & $0.405(0.274$ to 0.537$)$ & $<0.001$ \\
LVEF & $0.086(0.043$ to 0.129$)$ & $<0.001$ \\
\hline
\end{tabular}

$\mathrm{OR}$, odds ratio; $\mathrm{Cl}$, confidence interval; $\mathrm{VO}_{\text {2peak, }}$ peak oxygen uptake; LVEF, left ventricular ejection fraction; $\mathrm{VO}_{2 \mathrm{AT}}$, oxygen uptake at anaerobic threshold; $\mathrm{BMI}$, body mass index.

\section{Discussion}

To the best of our knowledge, the present study is the first to directly compare the effects of CR and IR on CPET carried out within one month in patients with MVD, as a measure of myocardial ischemia. The main findings of our study are that there were no obvious differences in CPET parameters between patients with CR and IR, and that CR was not found to be an independent predictor of these parameters. In addition, the peak oxygen pulse was reduced in patients with IR compared with those with SVD, and there was a tendency for the other CPET parameters to be lower in patients with MVD than in those with SVD. Therefore, we provide novel data showing that CR is not superior to IR in terms of CPET, and conclude that CR may not always offer benefit over IR with regard to the improvement of post-STEMI ischemia. This is of relevance to clinicians making management decisions, and implies that CR should not be an automatic choice for all patients with STEMI and MVD.

The current guidelines from the American College of Cardiology/American Heart Association [18,21] and the European Society of Cardiology [19] are of limited help when it comes to synthesizing the available evidence and informing clinical practice on the issues of MVD in patients undergoing primary PCI. These guidelines state that "although percutaneous coronary intervention in a non-infarct artery is not recommended in stable patients, it can be beneficial in hemodynamically compromised patients if the stenotic artery perfuses a large area of myocardium and the procedure can be performed efficiently." However, the low level of evidence (level C: "consensus opinion of experts, case studies, or standard of care") forming the basis of this statement limits the strength of this recommendation.
A recent systematic review and meta-analysis suggested that multivessel PCI in subjects with ongoing or recent STEMI and MVD in non-culprit vessels, although not being associated with a significant increase in adverse events, does not confer any meaningful clinical benefit [22]. Since our CEPT results also suggest that CR does not significantly improve CEPT parameters, we believe it is reasonable to recommend that multivessel revascularization should be only used in patients with instability or very high clinical risk, and that intervention should be deferred in most other subjects until the results of ischemia-proving tests are available. However, another study reported that although multivessel angioplasty during primary PCI for STEMI did not reduce the rate of major adverse cardiac events compared with culpritvessel-only $\mathrm{PCI}, \mathrm{CR}$ was associated with a lower rate of repeat revascularization after multivessel PCI [23].

The recent PRAMI trial showed that in patients with STEMI and MVD undergoing culprit artery PCI, preventive $\mathrm{PCI}$ in non-infarct coronary arteries with major stenosis significantly reduced the risk of further adverse cardiovascular events, compared with PCI limited to the culprit artery [24]. In contrast, in our study, we conclude that CR may not always offer benefit over IR with regard to the improvement of post-STEMI ischemia. This is of relevance to clinicians making management decisions, and implies that $\mathrm{CR}$ should not be an automatic choice for all patients with STEMI and MVD. In the PRAMI study, patients were randomized into two groups, and those with preventive PCI might not undergo CR (like in our study), and those without preventive PCI might otherwise undergo CR [24]. Therefore, the results from the PRAMI trial could not be compared with ours.

It has been suggested that all patients with MVD undergo stress testing shortly after full recovery (or even before discharge) in order to thoroughly appraise the ischemic burden of residual MVD, since it is not uncommon to overestimate the severity of stenosis in non-culprit vessels of patients with STEMI [25]. Electrocardiographic exercise stress testing is an approach that has been proven to be safe and useful after an otherwise uncomplicated MI, and can be performed either before discharge or later [17-19,21].

Still, there is no information concerning the impact of $\mathrm{CR}$ after PCI on exercise capacity measured in the early stages $(<1$ month) after acute STEMI. Although CPET is established as an important diagnostic modality for the clinical assessment of patients with heart failure, its potential utility for defining physiologic abnormalities in other patient populations is being increasingly recognized. Therefore, developing techniques that allow detection of ischemia or disturbances in $\mathrm{O}_{2}$ kinetics at an early stage, before the onset of ECG changes and symptoms, will improve diagnostic accuracy to allow suitable intervention 
before these later effects manifest. Belardinelli et al. [10] demonstrated that CPET was able to increase the sensitivity of the standard stress ECG from $46 \%$ to $87 \%$, and the specificity from $66 \%$ to $74 \%$. The physiologic basis for using CPET gas exchange measurements in patients with coronary artery stenosis was based on their ability to accurately identify the onset of ischemia-induced left ventricular (LV) dysfunction during physical exertion, and to precisely quantify the magnitude of the physiologic impairment [11]. The abnormal physiologic response to CPET may therefore be similar in patients with macro- and micro-vascular ischemia. Recently, a case report described the CPET abnormalities in a patient with suspected microvascular coronary artery disease (CAD), and the subsequent improvement in LV function following three weeks of medical therapy with the anti-ischemic drug ranolazine [26]. This would support the use of CPET for the assessment of ischemia severity in patients with CAD.

Our study found that two of the parameters of exercise capacity, namely $\mathrm{VO}_{2 \text { peak }}$ and $\mathrm{VO}_{2 \mathrm{AT}}$, were not significantly different in patients with SVD than in those with MVD, irrespective of whether or not they were completely revascularized. However, there did appear to be a trend for $\mathrm{VO}_{2 \text { peak }}$ and $\mathrm{VO}_{2 \mathrm{AT}}$ to be lower in MVD patients compared with SVD, which may be due to a sample size not large enough to detect this difference. The only significant difference observed was for the peak oxygen pulse, which was higher in the SVD group than in the IR group. It thus remains possible that patients with MVD, particularly those with IR, show impaired exercise capacity as measured using CPET, which may be due to a number of factors. Patients with STEMI are in a heightened thrombotic and inflammatory state and may be more prone to the adverse effects of multivessel PCI $[27,28]$. Furthermore, multivessel stenting could potentially have adverse effects secondary to side branch closure and distal embolization [29,30]. In addition, it is becoming increasingly recognized that micro-vascular ischemia is a significant cause of exertional intolerance and angina, which can be detected earlier by CPET. The similar performance (in terms of CPET) of patients with $C R$ and IR suggests that CR of macro-vascular stenosis may not be sufficient to restore the blood flow through micro-vessels, resulting in a comparable degree of ischemia.

\section{Limitations}

This study is not without limitations. First, this was a retrospective observational study, rather than a prospective study such as a randomized controlled trial. As a result, we cannot exclude the possibility of a selection bias. Indeed, it is possible that CR was attempted and encouraged in patients in whom it seemed more feasible or more clinically relevant. It is also possible that baseline differences in exercise performance may have existed prior to PCI, and that exercise performance before MI may have been an important determinant of exercise performance shortly after PCI, especially in a non-randomized study, with a small numbers of patients medicated with multiple drugs. Since MI is unpredictable, we could not directly measure pre-MI exercise performance, and would have to rely on indirect measures such as questionnaires, which was not possible in the present study due to its retrospective nature. Second, the amount of ischemia damage was not directly assessed (e.g. using magnetic resonance imaging, MRI), but was measured using Troponin I, which is nevertheless considered gold standard. Third, $97 \%$ of our sample had a Killip class 1, indicating that these patients were a low risk population. Achieving a complete $\mathrm{CR}$ might show more benefits in higher risk patients. Fourth, the treatment strategy was based on angiography evidences, and not on ischemia evidences. Finally, the choice of endpoints might affect the conclusion. In the present study, we used quantitative endpoints. However, studies using clinical and qualitative endpoints might provide inconsistent results [22]. An appropriately prospectively designed randomized controlled trial, with a larger cohort of participants and with clear measurements of ischemia (such as MRI), would allow for a more detailed assessment of the relative merits of $C R$ and IR in patients with MVD.

\section{Conclusions}

In patients with STEMI and MVD, achieving CR with PCI might not improve exercise capacity. Our results suggest that in patients with STEMI and MVD, attempting CR in all patients may not be the best strategy, and that decisions regarding PCI of the non-infarct vessel(s) may need to be guided by objective evidence of significant residual ischemia. A personalized approach should be advocated. However, further large, randomized trials are needed to confirm these findings.

\section{Abbreviations}

ACEl: Angiotensin-converting enzyme inhibitors; ANOVA: Analysis of variance; ARB: Angiotensin receptor blockers; BB: $\beta$-blockers; BMI: Body mass index; CABG: Coronary artery bypass grafting; CAD: Coronary artery disease; Cl: Confidence interval; CPET: Cardiopulmonary exercise testing; CR: Complete revascularization; IR: Incomplete revascularization; IRA: Infarct-related artery; LV: Left ventricular; LVEF: Left ventricular ejection fraction; MI: Myocardial infarction; MRI: Magnetic resonance imaging; MVD: Multivessel diasease; OR: Odds ratio; PCI: Percutaneous coronary intervention; SD: Standard deviation; STEMI: ST-elevation myocardial infarction; SVD: Single-vessel disease;

TIMI: Thrombolysis in myocardial infarction; $\mathrm{VO}_{2 A T}$ : Oxygen uptake at anaerobic threshold; $\mathrm{VO}_{\text {2peak: }}$ Peak oxygen uptake.

\section{Competing interests}

The authors declare that they have no competing interests.

\section{Authors' contributions}

WZ designed the study, performed CEPT, data collection and statistical analysis, and drafted the manuscript. JB performed CPET and data collection. 
FZ performed PCI and CPET. LG performed PCI. All authors read and approved the final manuscript.

\section{Acknowledgments}

This study was supported by The National Science \& Technology Pillar Program during the Eleventh Five-Year Plan Period: Establishment of an integrated system for CHD prevention and treatment (2006BAI01 A02) and by the National Natural Science Foundation of China (81030001).

Received: 13 June 2013 Accepted: 11 March 2014

Published: 19 March 2014

\section{References}

1. Kumar A, Cannon CP: Acute coronary syndromes: diagnosis and management, part II. Mayo Clin Proc 2009, 84(11):1021-1036. PubMed PMID: 19880693. Pubmed Central PMCID: 2770915. Epub 2009/11/03. eng.

2. Lamas GA, Escolar E, Faxon DP: Examining treatment of ST-elevation myocardial infarction: the importance of early intervention. J Cardiovasc Pharmacol Ther 2010, 15(1):6-16. PubMed PMID: 20061507. Epub 2010/01/ 12. eng.

3. Sorajja P, Gersh BJ, Cox DA, McLaughlin MG, Zimetbaum P, Costantini C, Stuckey T, Tcheng JE, Mehran R, Lansky AJ, Grines CL, Stone GW: Impact of multivessel disease on reperfusion success and clinical outcomes in patients undergoing primary percutaneous coronary intervention for acute myocardial infarction. Eur Heart J 2007, 28(14):1709-1716. PubMed PMID: 17556348. Epub 2007/06/09. eng.

4. Webb JG, Lowe AM, Sanborn TA, White HD, Sleeper LA, Carere RG, Buller CE, Wong SC, Boland J, Dzavik V, Porway M, Pate G, Bergman G, Hochman JS, SHOCK Investigators: Percutaneous coronary intervention for cardiogenic shock in the SHOCK trial. J Am Coll Cardiol 2003, 42(8):1380-1386. PubMed PMID: 14563578. Epub 2003/10/18. eng.

5. Chechi T, Vecchio S, Vittori G, Giuliani G, Lilli A, Spaziani G, Consoli L, Baldereschi G, Biondi-Zoccai GG, Sheiban I, Margheri M: ST-segment elevation myocardial infarction due to early and late stent thrombosis a new group of high-risk patients. J Am Coll Cardiol 2008, 51(25):2396-2402. PubMed PMID: 18565395. Epub 2008/06/21. eng.

6. Jeger RV, Pfisterer ME: Primary PCI in STEMI-dilemmas and controversies: multivessel disease in STEMI patients. Complete versus Culprit Vessel revascularization in acute ST-elevation myocardial infarction. Minerva Cardioangiol 2011, 59(3):225-233. PubMed PMID: 21516071. Epub 2011/04/ 26. eng.

7. Kodama S, Saito K, Tanaka S, Maki M, Yachi Y, Asumi M, Sugawara A, Totsuka K, Shimano H, Ohashi Y, Yamada N, Sone H: Cardiorespiratory fitness as a quantitative predictor of all-cause mortality and cardiovascular events in healthy men and women: a meta-analysis. JAMA 2009, 301(19):2024-2035. PubMed PMID: 19454641. Epub 2009/05/21. eng

8. Myers J, Prakash M, Froelicher V, Do D, Partington S, Atwood JE: Exercise capacity and mortality among men referred for exercise testing. N Engl I Med 2002, 346(11):793-801. PubMed PMID: 11893790. Epub 2002/03/15. eng.

9. Zafrir N, Fink G, Klainman E, Sulkes J, Spitzer S: Relation between aerobic capacity and extent of myocardial ischemia in patients with normal cardiac function. Am Heart J 1999, 138(6 Pt 1):1088-1092. PubMed PMID: 10577439. Epub 1999/11/30. eng.

10. Belardinelli R, Lacalaprice F, Carle F, Minnucci A, Cianci G, Perna G, D'Eusanio G: Exercise-induced myocardial ischaemia detected by cardiopulmonary exercise testing. Eur Heart J 2003, 24(14):1304-1313. PubMed PMID: 12871687. Epub 2003/07/23. eng.

11. Chaudhry S, Arena R, Wasserman K, Hansen JE, Lewis GD, Myers J, Chronos N, Boden WE: Exercise-induced myocardial ischemia detected by cardiopulmonary exercise testing. Am J Cardiol 2009, 103(5):615-619. PubMed PMID: 19231322. Pubmed Central PMCID: 3035935. Epub 2009/02/24. eng.

12. Barmeyer A, Meinertz T: Anaerobic threshold and maximal oxygen uptake in patients with coronary artery disease and stable angina before and after percutaneous transluminal coronary angioplasty. Cardiology 2002, 98(3):127-131. PubMed PMID: 12417811. Epub 2002/11/06. eng.

13. Adachi H, Koike A, Niwa A, Sato A, Takamoto T, Marumo F, Hiroe M: Percutaneous transluminal coronary angioplasty improves oxygen uptake kinetics during the onset of exercise in patients with coronary artery disease. Chest 2000, 118(2):329-335. PubMed PMID: 10936120. Epub 2000/08/11. eng.
14. Gensini GG: A more meaningful scoring system for determining the severity of coronary heart disease. Am J Cardiol 1983, 51(3):606. PubMed PMID: 6823874.

15. Kalarus Z, Lenarczyk R, Kowalczyk J, Kowalski O, Gasior M, Was T, Zebik T, Krupa H, Chodór P, Poloński L, Zembala M: Importance of complete revascularization in patients with acute myocardial infarction treated with percutaneous coronary intervention. Am Heart J 2007, 153(2):304-312. PubMed PMID: 17239694.

16. Meliga E, Fiorina C, Valgimigli M, Belli R, Gagnor A, Sheiban I, Resmini C, Tizzani E, Aranzulla T, Scrocca I, DE Benedictis M, Conte MR: Early angioguided complete revascularization versus culprit vessel PCI followed by ischemia-guided staged PCI in STEMI patients with multivessel disease. J Interv Cardiol 2011, 24(6):535-541. PubMed PMID: 22010970.

17. ATS/ACCP: Statement on cardiopulmonary exercise testing. Am J Respir Crit Care Med 2003, 167(2):211-277. PubMed PMID: 12524257. Epub 2003/01/14. eng.

18. Antman EM, Anbe DT, Armstrong PW, Bates ER, Green LA, Hand M, Hochman JS, Krumholz HM, Kushner FG, Lamas GA, Mullany CJ, Ornato JP, Pearle DL, Sloan MA, Smith SC Jr, Alpert JS, Anderson JL, Faxon DP, Fuster V, Gibbons RJ, Gregoratos G, Halperin JL, Hiratzka LF, Hunt SA, Jacobs AK, Ornato JP: ACC/AHA guidelines for the management of patients with ST-elevation myocardial infarction; A report of the American College of Cardiology/American Heart Association Task Force on Practice Guidelines (Committee to Revise the 1999 Guidelines for the Management of patients with acute myocardial infarction). J Am Coll Cardiol 2004, 44(3):E1-E211. PubMed PMID: 15358047. Epub 2004/09/11. Eng.

19. Task Force on the management of ST-segment elevation acute myocardial infarction of the European Society of Cardiology (ESC), Steg PG, James SK, Atar D, Badano LP, Blömstrom-Lundqvist C, Borger MA, Di Mario C, Dickstein K, Ducrocq $G$, Fernandez-Aviles F, Gershlick AH, Giannuzzi P, Halvorsen S, Huber K, Juni P, Kastrati A, Knuuti J, Lenzen MJ, Mahaffey KW, Valgimigli M, Van't Hof A, Widimsky P, Zahger D: ESC Guidelines for the management of acute myocardial infarction in patients presenting with ST-segment elevation. Eur Heart J 2012, 33 (20):2569-2619. PubMed PMID: 22922416. Epub 2012/08/28. eng.

20. Beaver WL, Wasserman K, Whipp BJ: A new method for detecting anaerobic threshold by gas exchange. J Appl Physiol 1986, 60(6):2020-2027. PubMed PMID: 3087938. Epub 1986/06/01. eng.

21. Smith SC Jr, Feldman TE, Hirshfeld JW Jr, Jacobs AK, Kern MJ, King SB 3rd, Morrison DA, O'Neil WW, Schaff HV, Whitlow PL, Williams DO, Antman EM, Adams CD, Anderson JL, Faxon DP, Fuster V, Halperin JL, Hiratzka LF, Hunt SA, Nishimura R, Ornato JP, Page RL, Riegel B, American College of Cardiology/American Heart Association Task Force on Practice Guidelines; ACC/AHA/SCAI Writing Committee to Update 2001 Guidelines for Percutaneous Coronary Intervention: ACC/AHA/SCAI 2005 guideline update for percutaneous coronary intervention: a report of the American College of Cardiology/American Heart Association Task Force on Practice Guidelines (ACC/AHA/SCAI Writing Committee to Update 2001 Guidelines for Percutaneous Coronary Intervention). Circulation 2006, 113(7):e166-286. PubMed PMID: 16490830. Epub 2006/02/24. eng.

22. Biondi-Zoccai G, Lotrionte M, Sheiban I: Management of multivessel coronary disease after ST-elevation myocardial infarction treated by primary coronary angioplasty. Am Heart J 2010, 160(6 Suppl):S28-35. PubMed PMID: 21147289. Epub 2010/12/22. eng.

23. Jo HS, Park JS, Sohn JW, Yoon JC, Sohn CW, Lee SH, Hong GR, Shin DG, Kim YJ, Jeong MH, Chae SC, Hur SH, Hong TJ, Seong IW, Chae JK, Rhew JY, Chae IH, Cho MC, Bae JH, Rha SW, Kim CJ, Choi DH, Jang YS, Yoon JH, Chung WS, Seung KB, Park SJ: Culprit-lesion-only versus multivessel revascularization using drug-eluting stents in patients with ST-segment elevation myocardial infarction: a Korean acute myocardial infarction registry-based analysis. Korean Circ J 2011, 41(12):718-725. PubMed PMID: 22259602. Pubmed Central PMCID: 22259602. Epub 2012/01/20. eng.

24. Wald DS, Morris JK, Wald NJ, Chase AJ, Edwards RJ, Hughes LO, Berry C, Oldroyd KG, PRAMI Investigators: Randomized trial of preventive angioplasty in myocardial infarction. N Eng/ J Med 2013, 369(12):1115-1123. PubMed PMID: 23991625

25. Hanratty CG, Koyama Y, Rasmussen HH, Nelson Gl, Hansen PS, Ward MR: Exaggeration of nonculprit stenosis severity during acute myocardial infarction: implications for immediate multivessel revascularization. J Am Coll Cardiol 2002, 40(5):911-916. PubMed PMID: 12225715. Epub 2002/09/13. eng.

26. Chaudhry S, Arena R, Wasserman K, Hansen JE, Lewis GD, Myers J, Belardinelli R, LaBudde B, Menasco N, Boden WE: The utility of cardiopulmonary exercise testing in the assessment of suspected microvascular ischemia. Int I Cardiol 2011, 148(1):e7-9. PubMed PMID: 19233492. Pubmed Central PMCID: 3062706. Epub 2009/02/24. eng. 
27. Kornowski R, Mehran R, Dangas G, Nikolsky E, Assali A, Claessen BE, Gersh BJ, Wong SC, Witzenbichler B, Guagliumi G, Dudek D, Fahy M, Lansky AJ, Stone GW, HORIZONS-AMI Trial Investigators: Prognostic impact of staged versus "one-time" multivessel percutaneous intervention in acute myocardial infarction: analysis from the HORIZONS-AMI (harmonizing outcomes with revascularization and stents in acute myocardial infarction) trial. J Am Coll Cardiol 2011, 58(7):704-711. PubMed PMID: 21816305. Epub 2011/08/06. eng.

28. Hannan EL, Samadashvili Z, Walford G, Holmes DR Jr, Jacobs AK, Stamato NJ, Venditti FJ, Sharma S, King SB 3rd: Culprit vessel percutaneous coronary intervention versus multivessel and staged percutaneous coronary intervention for ST-segment elevation myocardial infarction patients with multivessel disease. JACC Cardiovasc Interv 2010, 3(1):22-831. PubMed PMID: 20129564. Epub 2010/02/05. eng

29. Shishehbor MH, Lauer MS, Singh IM, Chew DP, Karha J, Brener SJ, Moliterno DJ, Ellis SG, Topol EJ, Bhatt DL: In unstable angina or non-ST-segment acute coronary syndrome, should patients with multivessel coronary artery disease undergo multivessel or culprit-only stenting? J Am Coll Cardiol 2007, 49(8):849-854. PubMed PMID: 17320742. Epub 2007/02/27. eng.

30. Varani E, Balducelli M, Aquilina M, Vecchi G, Hussien MN, Frassineti V, Maresta A: Single or multivessel percutaneous coronary intervention in ST-elevation myocardial infarction patients. Catheter Cardiovasc Interv 2008, 72(7):927-933. PubMed PMID: 18798239. Epub 2008/09/18. eng.

doi:10.1186/1749-8090-9-50

Cite this article as: Zhao et al: Impact of completeness of revascularization by coronary intervention on exercise capacity early after acute ST-elevation myocardial infarction. Journal of Cardiothoracic Surgery 2014 9:50.

\section{Submit your next manuscript to BioMed Central and take full advantage of:}

- Convenient online submission

- Thorough peer review

- No space constraints or color figure charges

- Immediate publication on acceptance

- Inclusion in PubMed, CAS, Scopus and Google Scholar

- Research which is freely available for redistribution 